\title{
INCIDÊNCIA DE ÓBITOS POR MENINGITE NO BRASIL E NO TOCANTINS ENTRE 2010 E 2015
}

INCIDENCE OF DEATHS BY MENINGITIS IN BRAZIL AND
TOCANTINS BETWEEN 2010 AND 2015

\section{fิ ACESSO LIVRE}

Citação: Souza AR, Medeiros LR, Julliany Nascimento JMS, Silva WB, Oliveira JDD (2018) Incidência de óbitos por meningite no Brasil e no Tocantins entre 2010 e 2015. Revista de Patologia do Tocantins, 5(4): 17-19.

Instituição: 'Acadêmico(a) do Curso de Medicina da Universidade Federal do Tocantins; ${ }^{2}$ Bióloga, Doutora em Genética e Bioquímica, Docente Adjunta do Curso de Medicina da Universidade Federal do Tocantins.

Autor correspondente: Aline Rangel de Souza; aliners1997@gmail.com

Editor: Guedes V. R. Medicina, Universidade Federal do Tocantins, Brasil.

Publicado: 09 de dezembro de 2018.

Direitos Autorais: (c) 2018 Souza et al. Este é um artigo de acesso aberto que permite o uso, a distribuição e a reprodução sem restrições em qualquer meio, desde que o autor original e a fonte sejam creditados.

Conflito de interesses: os autores declararam que não existem conflitos de interesses. Aline Rangel de Souza', Lorena Resende Medeiros ${ }^{1}$, Julliany Mirelly Sousa
Nascimento', Wanderson Batista Silva', Jaqueline das Dores Dias Oliveira ${ }^{2}$.

\section{RESUMO}

Introdução: A meningite é caracterizada pela inflamação das meninges, possuindo diversos fatores causais, infecciosos ou não. A etiologia viral é a mais incidente, entretanto a mais importante do ponto de vista de mortalidade é a bacteriana. Embora a região Norte do Brasil seja considerada zona endêmica de doenças infectocontagiosas, poucos são os estudos publicados que abordam fatores envolvidos na disseminação populacional desses agravos. O objetivo desse trabalho foi o estabelecimento e comparação dos coeficientes de incidência (CI) de óbitos pela doença no Brasil e Tocantins entre 2010 e 2015 . Material e Métodos: Trata-se de um estudo epidemiológico e transversal realizado com dados obtidos do total de notificações no SINAN, entre os períodos de 2010 a 2015. Resultados: Em 2010, no Brasil, houve 3003 casos relatados de doença meningocócica, com $\mathrm{Cl}$ de 617 óbitos/100.000 habitantes. Já em 2015, o Cl foi de 243 óbitos/100.000 habitantes. No Tocantins, em 2010, houve 62 óbitos da doença meningocócica, em 2011, 63 óbitos, em 2012, 73 óbitos, em 2013, 74 óbitos, em 2014, 71 óbitos e em 2015, 33 óbitos. Resultando, nos respectivos $\mathrm{Cl}: 4,4 ; 4,4 ; 5,0 ; 5,0 ; 4,7$ e 2,2 óbitos/100.000 habitantes. Discussão: Os achados apontam para uma superioridade proporcional do Brasil em relação ao Tocantins no número de casos, assim como de óbitos. Isso pode ser em detrimento, tanto de no Brasil haver regiões endêmicas e, portanto, com maior taxa de detecção, como por subnotificação no caso do Tocantins, que é um fator recorrente nos estados da região Norte do Brasil. Conclusão: o $\mathrm{Cl}$ de óbitos por meningite no Tocantins é inferior ao do Brasil e esse $\mathrm{Cl}$ se manteve estável no recorte temporal analisado. Este estudo sugere a importância de relatos de casos na região, além do protagonismo da eficiência dos sistemas de detecção e notificação para o planejamento do serviço assistencial.

Palavras-chave: Epidemiologia; Infecções Meningocócicas; Infectologia; Medicina Tropical; Meningite.

\section{ABSTRACT}

Introduction: Meningitis is characterized by the inflammation of the meninges, having several causal factors, infectious or not. The viral etiology is the most frequent, however the most important from the point of view of mortality is bacterial. Although the northern region of Brazil is considered an endemic area of infectious diseases, few published studies address factors involved in the dissemination of these diseases. The objective of this study was the establishment and comparison of the incidence coefficients (IC) of deaths by the disease in Brazil and Tocantins between 2010 and 2015. Material and Methods: This is an epidemiological and cross-sectional study with data obtained from total notifications in SINAN between 2010 and 2015. Results: In 2010, in Brazil, there were 3003 reported cases of meningococcal disease, with a IC of 617 deaths / 100,000 inhabitants. By 2015, the IC was 243 deaths / 100,000 inhabitants. In Tocantins, in 2010, there were 62 deaths from meningococcal disease in 2011, 63 deaths in 2012, 73 deaths in 2013, 74 deaths in 2014, 71 deaths and in 2015, 33 deaths. Resulting, in the respective ICs: 4.4; 4.4; 5.0; 5.0; 4.7 and 2.2 deaths / 100,000 inhabitants. Discussion: The findings point to a proportional superiority of Brazil in relation to Tocantins in the number of cases, as well as deaths. This may be detrimental to the fact that in Brazil there are endemic regions and, therefore, with a higher rate of detection, as by underreporting in the case of Tocantins, which is a recurring factor in the northern Brazilian states. Conclusion: The IC of meningitis deaths in Tocantins is lower than in Brazil and this IC remained stable in the temporal cut analyzed. This study suggests the importance of case reports in the region, as well as the role of the detection and notification systems for the planning of care services.

Keywords: Epidemiology; Infectious Disease Medicine; Meningitis; Meningococcal Infections; Tropical Medicine. 


\section{INTRODUÇÃO}

A meningite, que é uma doença infectocontagiosa caracterizada pela inflamação das meninges, possui diversos fatores causais, infecciosos ou não. Dentre as causas infecciosas, as principais são de etiologia viral ou bacteriana. Também, cistos ou tumores intracerebrais, medicamentos e doenças inflamatórias poderão desencadear o processo de irritação meníngea, instalando, pois, o conjunto sindrômico que marca o espectro clínico das meningites ${ }^{1}$.

A etiologia mais frequente da meningite, no Brasil, é a viral, entretanto a bacteriana é relatada como importante causa de mortalidade, chegando a $18,2 \%$ em comparação com as meningites virais $(3,4 \%)$ e ocorrendo, principalmente, em crianças de países de baixa renda ${ }^{2}$.

Dentre as meningites bacterianas, o agente etiológico envolvido no processo pode variar de acordo com a região do país. Nesse sentido, um estudo realizado em Salvador-BA, apontou Neisseria meningitidis como principal agente etiológico bacteriano naquela região, seguido de Streptococcus pneumoniae, Mycobacterium tuberculosis e Haemophilus influenzae. Porém a maior mortalidade, de acordo com aquele estudo, foi para $M$. tuberculosis, com uma taxa de $51,2 \%$ para a população e $60 \%$ para crianças menores de 5 anos, seguidas de $S$. pneumoniae, $N$. meningitidis e $H$. influenzae ${ }^{3}$. Em relação ao cenário nacional, a forma viral é a mais incidente, entretanto de comportamento mais benigno quando comparada à bacteriana ${ }^{2,6}$.

De um modo geral, a meningite bacteriana é a mais grave e, dentre elas, merece atenção especial a Doença Meningocócica (DM), que pode se apresentar como Meningite Meningocócica, (MM); e/ou Meningococcemia, (MMCC); e a Meningite por Haemophilus influenzae (Hib), que são causas importantes de óbitos no Brasil7.

O quadro clínico, independente da etiologia, pode caracterizar-se por febre, vômito, cefaleia, rigidez nucal, petéquias, coma, sinal de Kernig e/ou Brudzinski, e, quando grave, levar ao óbito. Nesse sentido, estudos relataram óbito como desfecho em $15 \%$ dos casos de meningite, sendo as de causa bacteriana responsável por $91,7 \%$ do total de mortes ${ }^{4}$, sendo os casos de DM importante constituinte desse indicador 7 .

A região Norte do Brasil é considerada zona endêmica de doenças infectocontagiosas, dentre as quais hanseníase, síndrome da imunodeficiência humana adquirida (AIDS), leishmaniose, malária, leptospirose, tuberculose, e, ainda, configura local de doenças reemergentes como cólera e febre tifoide $^{5}$. Apesar do impacto social que a meningite apresenta para a região, poucos são os estudos publicados tendo a região Norte do país como alvo de análise. Desse modo, o objetivo desse trabalho foi o estabelecimento do coeficiente de incidência da doença no Brasil entre 2010 a 2015, comparando-se às notificações do Tocantins e, ainda, discutir os eventuais elementos no bojo dos índices encontrados.

\section{MATERIAL E MÉTODOS}

Trata-se de um estudo epidemiológico e transversal que foi realizado com dados obtidos por meio do montante de notificações no Sistema de Notificações de Agravos
Notificáveis (SINAN). Os dados foram extraídos do Sistema de Informática do Ministério da Saúde (DATASUS), contemplando o recorte temporal de seis anos, indo de 2010 a 2015.

Os números foram tabulados e tratados por meio de planilhas eletrônicas do Microsoft Excel, sendo, então, discutidos e construídas as inferências conjuntamente com estatísticas descritivas. Por serem dados públicos, disponíveis on-line, sem identificação pessoal ou institucional, não houve necessidade de aprovação do estudo em Comitê de Ética, porém foram respeitados os ditames trazidos pela Declaração de Helsinque para pesquisas da área médica.

Quanto à sua importância, os achados possuem abrangência nacional, sendo identificados no período de 2010 a 2015, tanto para o Brasil, como para o Tocantins. Os coeficientes de incidência foram calculados tomando como base o número absoluto de óbitos notificados por meningite (incidência), compondo o numerador; e a população oficial do Tocantins compondo o denominador e assim foram categorizadas as incidências gerais do Brasil e do Tocantins, permitindo o levantamento de hipóteses e suas respectivas discussões.

\section{RESULTADOS E DISCUSSÃO}

Em 2010, no Brasil, houve 3003 casos relatados de doença meningocócica com 617 óbitos. Já em 2015, foram 1105 casos, com 243 óbitos (Figura 1), resultando nos respectivos coeficientes de incidência: 0,31 óbitos /100.000 habitantes em 2010 e 0,12 óbitos/ 100.000 habitantes. No Tocantins, no ano de 2010, foram notificados 62 óbitos da doença meningocócica, em 2011, 63 óbitos, em 2012, 73 óbitos, em 2013, 74 óbitos, em 2014, 71 óbitos e em 2015, 33 óbitos. Tais notificações foram transformadas em um coeficiente de incidência, conforme Figura 2, para melhor representar os dados de cada ano para o estado do Tocantins.

Os dados apontam uma superioridade proporcional durante o período observado em nível nacional com relação ao Tocantins no número de casos, assim como de óbitos. Isso pode ser em detrimento, tanto de no Brasil haver regiões endêmicas e, portanto, com maior taxa de detecção, como por subnotificação no caso do Tocantins, um fator recorrente nos estados da região Norte do Brasil.

Em relação ao panorama nacional, estudos apontam que os estados de São Paulo e Rio de Janeiro possuíam os maiores coeficientes de incidência de óbitos por meningites no ano de $2013^{8}$. Em contrapartida, os menores coeficientes naquele mesmo ano foram registrados pelos estados do Acre e Roraima ${ }^{8}$, ambos da região Norte do Brasil, o que só reforça a hipótese de que esse agravo é subnotificado nos estados da região, sendo que esses locais são endêmicos e propícios para doenças infectocontagiosas, tanto por suas características bióticas, quanto abióticas e também socioculturais ${ }^{5}$. 


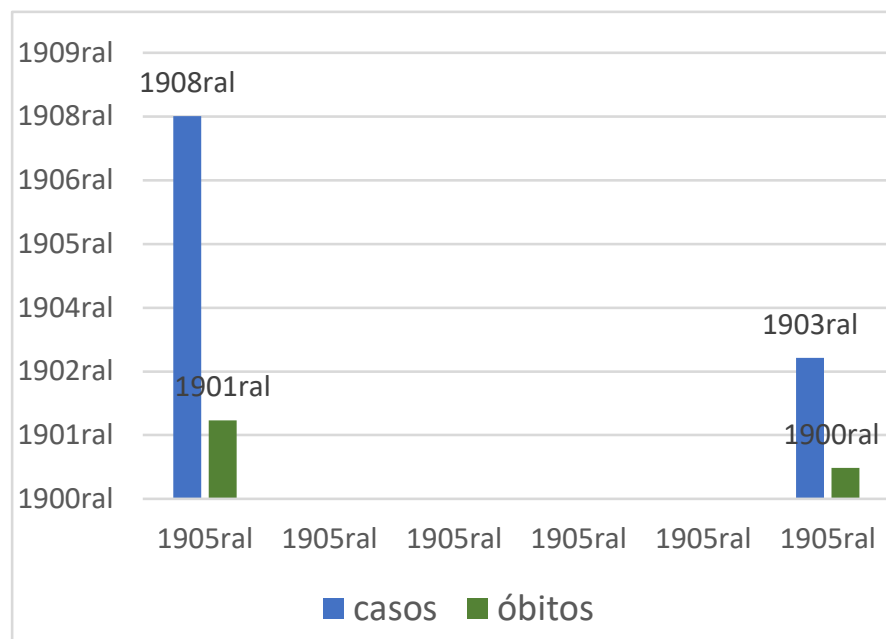

Figura 1: Casos e óbitos de meningite no Brasil 2010 e 2015

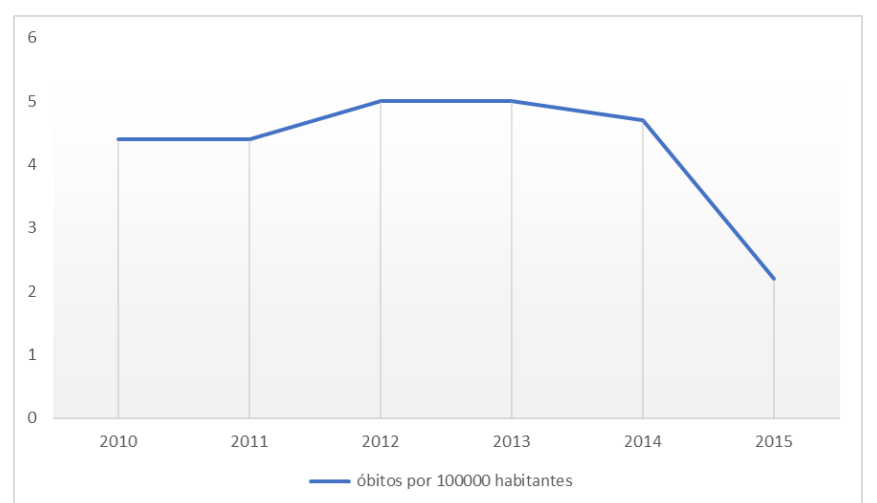

Figura 2: Tocantins, óbitos de meningite por 100.000 habitantes 2010-2015

\section{CONCLUSÕES}

Conclui-se que o coeficiente de incidência da meningite no Tocantins é inferior ao do Brasil, sendo que o coeficiente de óbitos foi maior em relação ao observado para o Brasil e que esse coeficiente se manteve estável no recorte temporal analisado, sendo observado um leve decréscimo no último ano observado. Este estudo sugere a importância de relatos de casos na região, além da importância da eficiência dos sistemas de detecção e notificação para o planejamento do serviço, sendo importante as redes de vigilância epidemiológicas, que são parte do sistema de saúde estruturado no Brasil. Uma melhor qualidade dos dados notificados e, portanto, das informações disponíveis podem reordenar a atenção, voltando-a pra os agravos mais presentes, antecipando a intervenção, favorecendo a prevenção primária e desonerando os demais níveis de complexidade.

\section{REFERÊNCIAS BIBLIOGRÁFICAS}

1- Bennett J, Dolin R, Blaser M; Principles and Practice of Infectious Diseases; seventh edition, 2011.

2-Greenhill AR, Phuanukoonnon S, Michael A, Yoannes M, Orami T, Smith H, Murphy D, Blyth C, Jeeder J, Siba P, Pomat W, Lehmann D. Streptococcus pneumoniae and Haemophilus influenzae in paediatric meningitis patients at Goroka General Hospital, Papua New Guinea: serotype distribution and antimicrobial susceptibility in the prevaccine era. BMC Infect Dis. 2015; 15: 485.

3-Rogerio LPW, Camargo RPM, Menegali TT, da Silva RM. Perfil epidemiológico das meningites no sul de Santa Catarina entre 1994 e 2009. Rev Bras Clin Med. São Paulo, 2011 mai-jun;9(3):200-3.

4-Azevedo LCP, Toscano CM, Bierrenbach AL. Bacterial Meningitis in Brazil: Baseline Epidemiologic Assessment of the Decade Prior to the Introduction of Pneumococcal and Meningococcal Vaccines. PLoS ONE 2013 8(6): e64524. doi:10.1371/journal.pone.0064524.

5-Martins M, Lacerda MV, Monteiro WM, Moura MA, Santos EC, Saraceni V, Saraiva MG. Progression of the load of waterborne and intestinal parasitic diseases in the State of Amazonas. Rev Soc Bras Med Trop. 2015; 48 Suppl 1:42-54. doi: 10.1590/0037-8682-01622014

6-Ministério da Saúde. Vigilância Epidemiológica: Meningites em Geral e Doença Meningocócica. Florianópolis: Ministério da Saúde, 2014. 6 p.

7-Guia de vigilância epidemiológica / Ministério da Saúde, Secretaria de Vigilância em Saúde, Departamento de Vigilância Epidemiológica. - 7. ed. - Brasília: Ministério da Saúde, 2009. 816 p.

8-Boletim Epidemiológico Secretaria de Vigilância em Saúde Ministério da Saúde Volume 47 №29, 2016. 